\title{
DOING PHENOMENOLOGY TOGETHER IN DIFFERENT WAYS
}

\section{HACIENDO FENOMENOLOGÍA JUNTOS DE DIFERENTES MANERAS}

Toru Tani

Ritsumeikan University, Kyoto

tanityk3@mtg.biglobe.ne.jp

I don't remember exactly which year it was that I first met Lester Embree. I think it was sometime in the early 80s. I was a doctoral candidate at Keio University in Tokyo and he was a visiting lecturer at Musashi University, also in Tokyo. We met at a phenomenological conference of some kind and were introduced by Hiroshi Kojima, professor of philosophy at Kanto-gakuin University and later Niigata University and a longtime colleague and friend of Lester's. Kojima had planned to accompany Lester to Kamakura after the conference but suddenly couldn't make it, so he asked me to go instead. (This was meant more as a favor to me than to Lester, because I was taking my first steps in an academic career and Kojima felt that Lester was someone I should know.)

The next day, I headed to Lester's station to pick him up, together with my then-girlfriend and present wife as moral and linguistic support, since she had spent ten years of her childhood in the United States. We went to Kamakura together and looked at several temples, visited Nishida Kitaro's grave and had lunch together, all the while discussing philosophy in general and Japanese phenomenologists in particular. Lester impressed me as being big, friendly and straightforward and personally acquainted with more phenomenologists than anyone I had ever known.

We remained in touch after that, even after I left the Tokyo area for my first fulltime teaching position, but it was after the coming of the internet and realtime email exchanges that our relationship really took hold. Lester was always 
full of projects and he was especially dedicated to connecting people and getting them to work together to promote phenomenology. I, on my part, was of an age and position where I was recruited for the administrative chores of various academic circles-which meant that I had access to numerous lists and knew who was doing what and where. So Lester would often email me to ask if I knew someone who was working on such-and-such because he wanted to organize a conference or put together a volume around that problem and wanted someone from Japan to be involved. I was handy and energetic back in those days, and my wife was an added bonus because she could write quick replies in English.

It was during those years that Lester poured his considerable energy into building up organizations like P.E.A.CE. (Phenomenology for the East Asian CirclE) and O.P.O. (Organization of Phenomenological Organizations). He was all over the globe, talking to people, getting them to talk to each other, persuading them to set up networks (and doing a lot of the work himself), organizing conferences, working on funding issues, setting up publications. I received invitations to Lester-related conferences several times a year, most of which I was unable to attend, but when I did manage to attend something in Japan or Europe, I could expect to meet him there. I never ceased to be amazed at his unflagging energy.

Lester was often in Japan, stirring things up. He loved to drag us out of our academic shells and goad us into doing things with other institutions, with people from other fields, with other countries. Japan, South Korea and China share a long history and culture and have much to learn from each other, but researchers in those countries, myself included, tended to pass over Asia and fly to Europe or the U.S. when in need of outside stimulus. Lester, however, was determined to get us to work together. As far as he was concerned, borders and barriers were there to be crossed and the all-important thing was to Do Phenomenology. He was always so energetic and big-hearted, and he paid such little heed to our hesitations, that we mostly follow him where he led.

Over the past two decades, I have developed some very warm and productive relationships with colleagues in South Korea, mainland China, Hong Kong and Taiwan. We now invite each other to conferences and share projects unrelated to O.P.O. or P.E.A.CE. I have learned a great deal from these Asian colleagues and benefit from our interaction. We might have managed it ourselves, but Lester played a large role in getting us started. 
Aside from connecting me to many people, Lester invited me several times to contribute articles to books he was editing. The two I remember best was a piece I wrote about Watsuji for his Phenomenological Approaches to Moral Philosophy and another in which I presented a brief history of Japanese phenomenology for his retrospective Husserl's Ideen. I have a tendency to write much more than I am supposed to and Lester helped me to shorten my article. He went over it many times for me, commenting, making suggestions, slashing what he considered dispensable. We were both aware that our minds worked in very different ways. Lester was always stubbornly practical and he liked things to be clear and connected to the concrete world. He was good at cutting away the chaff. He was also impatient with (what he regarded as) too much abstraction and metaphysical thinking. I, on the other hand, am just as stubbornly abstract and metaphysical, because these are the aspects that seem most real to me. We both recognized these differences and accepted them, I think. He was patient with me, hoping that someday I would see the light and head in his direction. I, on the other hand, tried to stick as closely as possible to concrete matters when I wrote something for Lester. We never quite met at the theoretical level, but we both knew that we were ultimately connected in being part of the phenomenological movement.

Lester, I am sorry that we did not have more time to do phenomenology together, just like as Husserl undertook "do philosophy together" (synphilosophein). We might have reformed each other more. I will miss seeing you at every phenomenological conference. I will miss not receiving a Winter Solstice message from you each year in late December. We will all miss the way you stirred up the phenomenologists of the world. 